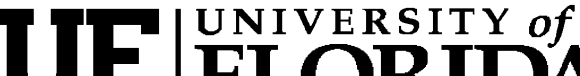 FLORIDA \\ IFAS Extension
}

\section{Seed Production of Leavenworth's Coreopsis ${ }^{1}$}

Jeffrey G. Norcini²

\section{Species Description}

The genus Coreopsis is Florida's State Wildflower. Coreopsis leavenworthii, Leavenworth's coreopsis or Leavenworth's tickseed, is nearly endemic to Florida. Except for its occurrence in two Alabama counties (1), its worldwide distribution is limited to Florida. Leavenworth's coreopsis is found in most Florida counties, and typically grows in roadside ditches, wet pine flatwoods, and other moist, disturbed sites.

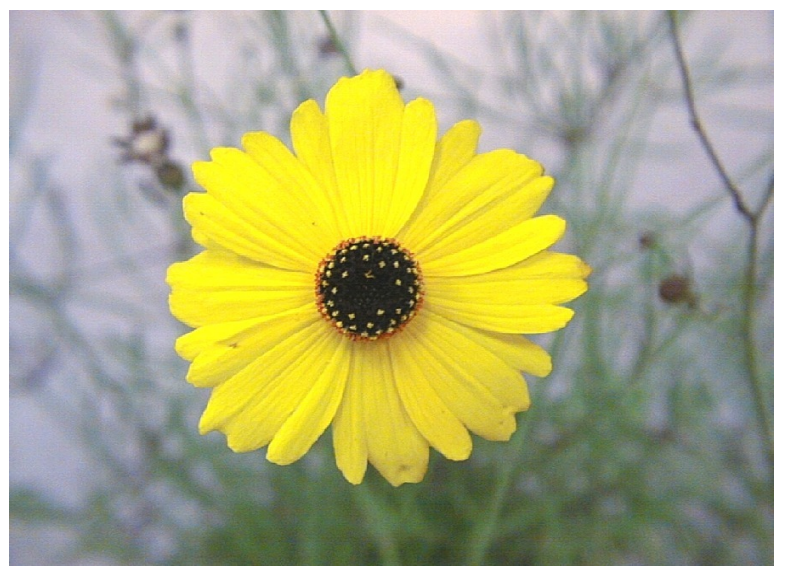

Figure 1. Close up of Leavenworth's coreopsis flower.
It is an upright plant with narrow pinnately to bipinnately compound leaves. Plants are usually $11 / 2$ to 3 feet tall. The flowers, which are typically $3 / 4$ to $11 / 2$ inches in diameter, have showy yellow ray flowers with brownish disk flowers (Figure 1). Blooming season under natural conditions ranges from summer in north Florida to year-round in south Florida, although planted populations in north Florida have started blooming as early as late spring. Leavenworth's coreopsis typically is an annual under natural conditions in north Florida. It tends to become more of a short-lived herbaceous perennial in central Florida, and a short-lived herbaceous/evergreen perennial in south Florida.

\section{Seed Origin}

Seed originating from naturally occurring populations and that has not been subjected to a process of selecting for desirable traits is commonly referred to as Florida ecotype, "Yellow Tag (natural track)", or "Source Identified (natural track)" (4). For additional information, see Seed Testing and Certification. To receive this designation, the grower must have the seed crop certified as to the Florida county of the original, naturally occurring population(s). This type of seed commands a high

\footnotetext{
1. This document is ENH 868, one of a series of the Environmental Horticulture Department, Florida Cooperative Extension Service, Institute of Food and Agricultural Sciences, University of Florida. Original publication date September 2002; revised August 2006. Visit the EDIS Web Site at http://edis.ifas.ufl.edu.

2. Jeffrey G. Norcini, Associate Professor, native wildflower specialist, North Florida Research \& Education Center, Quincy, FL 32351.

The use of trade names in this publication is solely for the purpose of providing specific information. UF/IFAS does not guarantee or warranty the products named, and references to them in this publication does not signify our approval to the exclusion of other products of suitable composition.
} 
price because plants derived from this seed are adapted to Florida's climate. Being adapted to Florida's climate means that these plants should perform better in noncultivated sites-like roadsides, meadows, and natural areas - than plants derived from other regions of the country. Moreover, since these plants are adapted to Florida's climate, the current thinking among many in the scientific community is that Florida ecotypes should be grown in Florida.

Two excellent articles that address the issue of seed origin in detail are "Genetic Principles and the Use of Native Seeds -- Just the FAQs, Please, Just the FAQs" (4) and "Native Seeds in Commerce: More Frequently Asked Questions" (5).

\section{Establishment and Maintenance}

Leavenworth's coreopsis can be grown in a traditional field planting (Figure 2) or in a landscape fabric system (Figure 3). While a traditional field planting is a less expensive option, potential yields should probably be greater with a landscape fabric seed production system based on the yield data obtained from Florida growers.

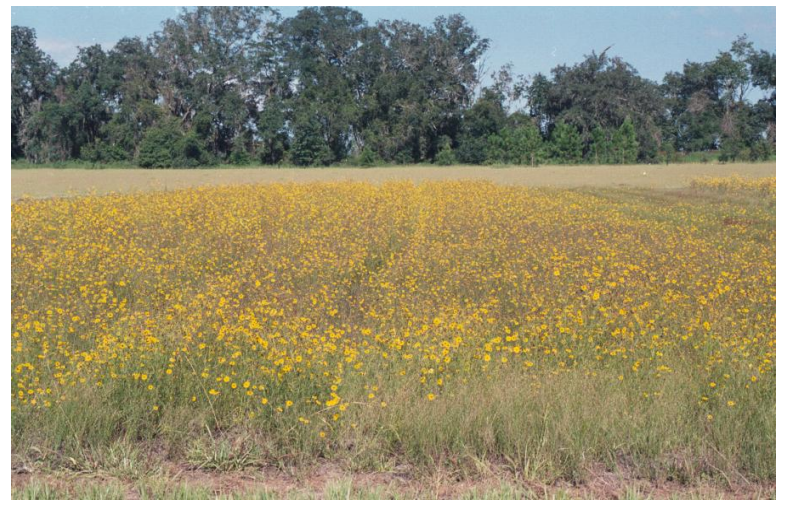

Figure 2. Field planting of Leavenworth's coreopsis. Credits:

In a landscape fabric system, plants are grown in narrow rows created by a 2- to 4-inch gap between parallel strips of woven landscape fabric. Plastic film is discouraged because it will limit rain from reaching the roots. Also, rain water could pool on the plastic and wash seed away. While plastic is less expensive than woven fabric, plastic might only last 1 year, whereas fabric could last 5 to 7 years.

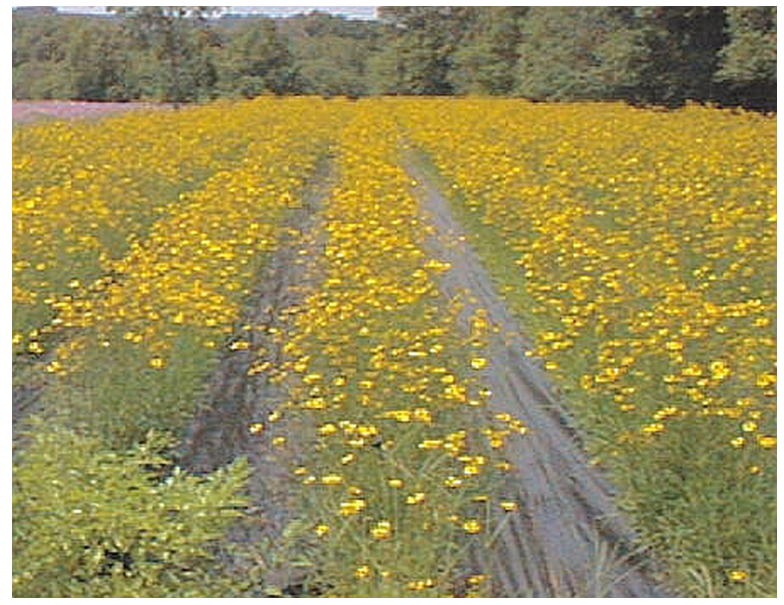

Figure 3. Leavenworth's coreopsis in a landscape fabric cropping system.

\section{Site Selection}

Select a site with the goal of minimizing weed growth. For more information about weeds, see Weed Control. Identify weeds in and around the site prior to planting so that you know what weed problems might be encountered and can plan on practices to control them. To minimize weed growth:

Choose a site with a sparse weed population. At sites where weed growth is dense, there is probably a substantial weed seed bank in the top 2 to 3 inches of soil. Inhibiting germination and growth of weeds at sites that strongly support their presence could be costly or futile. However, sparse weed growth could be due to extremely compacted soil.

Avoid sites with heavily compacted soils as well, since making these sites suitable for production could be costly.

Avoid sites with a considerable amount of yellow or purple nutgrass (Cyperus esculentus and Cyperus rotundus, respectively). These species spread rapidly, are extremely competitive, and are difficult to eliminate.

If the site is in turf, choose an area where the turf cover is thin or moderate. Avoid areas of thick turf. While grass herbicides can help control grasses, site conditions that support thick turf would probably favor weed growth as well. 


\section{Site Preparation}

Most aspects of site preparation are similar for both traditional field plantings and landscape fabric systems, and for both seed and transplant establishment of the production site.

Minimum Till. About 4 weeks before planting, kill existing vegetation with a nonselective, translocated herbicide that contains either glyphosate or glufosinate as the only active ingredient. More than one application will probably be needed to kill the weeds, so make the second application about 2 weeks after the first one. About 2 weeks after the second application, mow the dead vegetation down close to the soil and either bag the clippings, direct the mower discharge so that clippings are discharged off the planting site, or, if permitted, burn off the dead vegetation.

\section{Using Seed}

Field planting. Lightly scarify the field with a disk or harrow so that the soil surface is barely scratched. Disking or harrowing at least one time in a perpendicular direction will increase the amount of soil surface that is scarified. Lightly scarifying the soil facilitates good seed-to-soil contact while minimizing the soil disturbance that creates weed problems. Disking or harrowing will not be necessary if a no-till drill is used to sow the seed, and will probably not be necessary if the soil is sandy. However, if the seed bed soil is loose, it will have to be made firmer. A turf roller or cultipacker can be used to firm up the seed bed.

Landscape fabric system. Delineate the row locations and then lightly disk or harrow the rows only. If the soil is loose, only roll or cultipack the rows.

\section{Using Transplants}

No further site preparation is necessary, unless irrigation will be installed, which is discussed at the end of this section.

Deep Till. While the minimum till method avoids weed competition by reducing soil disturbance, the goal of the deep till method is to substantially deplete the weed seed bank in the soil. This method will result in a well tilled soil and minimal weed competition, but it can take up to 2 years to complete.

Existing vegetation is killed with a nonselective, translocated herbicide containing either glyphosate or glufosinate as the only active ingredient. The field is then deep tilled and a new crop of weeds is allowed to emerge. When weed seedlings are 1 to 3 inches tall, kill them as before. Repeat this herbicide/tilling cycle for up to 2 years. Since the soil is deep tilled, it will have to be firmed up before planting, as previously mentioned.

Soil Solarization. This is a cultural method of pest control in which clear polyethylene is laid over moist, tilled soil for 6 to 12 weeks to trap incoming solar radiation, thereby heating the soil to temperatures lethal to many weed species and soil-borne pests. Several points to keep in mind are:

- Use this method only in summer or early fall, when the soil temperature is easiest to increase and maintain.

- This method will only control/suppress soil pests to a depth of 6 to 8 inches.

- Soil must be kept moist.

- Some crabgrass species may not be controlled.

Additional information about this technique can be found in Florida Cooperative Extension Service publication ENY625, "Nematodes and Their Management" (http://edis.ifas.ufl.edu/CV112).

Once the soil is prepared, consider installing an irrigation system so that plants can be irrigated during extended dry periods. Flowering season of natural stands is extended when rain occurs regularly. And just as important, water stress may affect seed yield and quality. While an irrigation system is certainly beneficial, the cost of installing a new one for a field planting may be prohibitive and therefore not practical.

\section{Planting}

\section{Using Seed}


Sow about $2 \mathrm{lb}$ Pure Live Seed (PLS) per acre in late summer or early fall while temperatures are warm and before the end of the rainy season. This seeding rate should yield a stand dense enough to help reduce weed competition. Best stand establishment will occur with frequent rain or supplemental irrigation (1/4 inch water per day) for the first 2 to 3 weeks after seed is sown. Seedlings (Figure $\mathrm{x}$ ) will form rosettes and remain at this stage until the weather warms up in the spring.

Field Planting. Production fields can be established as solid stands or in rows. Space rows far enough apart so that you can use a cultivator to control weeds.

A no-till seed drill, if available, can be used to plant large, solid stands. To obtain spaced rows, cover the drop tube holes in the seed drill hopper that are necessary to obtain the desired row spacing.

Good seed-to-soil contact is critical for optimal germination. Therefore, if seed is not planted with a no-till seed drill, cultipack or roll the seed bed, or simply scratch the seed into the soil with a rake. Best seedling emergence should occur when seed are in the top $1 / 8$ to $1 / 4$ inch. Seed buried deeper than $3 / 8$ inches might germinate but seedlings might not emerge.

To uniformly distribute seed by hand over an entire small plot (less than 1 acre), mix half the seed with slightly moistened sand or a similar inert material. The ratio of sand to seed (by volume) should be 9:1 or greater. Spread this half of the seed over the entire plot, and then repeat the entire process with the other half of the seed. Incorporate the seed as described above for good soil-to-seed contact.

Landscape Fabric System. Sow seeds with a mechanical planter to ensure even distribution within the narrow row. After the seed is sown, incorporate the seed into the top $1 / 8$ to $1 / 4$ inch of soil by rolling or simply walking down the row in flat-soled shoes.

\section{Using Transplants}

Plant seedlings in early fall so they can develop a good root system and harden off before the first frost or freeze. However, in south Florida, transplanting by mid-December should be acceptable. Seedlings to be transplanted should have a well-developed root system but not be root bound. Space plants about 12 inches on center; use closer spacing on sandy soils. Seedlings will require frequent watering (rain or supplemental irrigation) for the first 2 to 3 weeks after transplanting.

\section{Fertilization}

While the effects of supplemental fertilization have not been evaluated in field or landscape fabric plantings of Leavenworth's coreopsis, seed production of container-grown Leavenworth's Coreopsis was directly related to fertilization rate (8). Fertilizer increased flowering, which resulted in a concomittant increase in number of seed. The current recommendation for Leavenworth's coreopsis is to apply up to $35 \mathrm{lb} \mathrm{N}$ per growing season. Apply a fertilizer with a low $\mathrm{N}$, low to no phosphorus (P), and high potassium (K) ratio (for example, 5-0-20 or 5-5-20). And consider that excess nitrogen may promote vegetative growth over flower production. Decisions about fertilization should be based on a soil test, which should be conducted annually to determine levels of $\mathrm{P}$ and $\mathrm{K}$.

Supplemental fertilization should begin in late February or early March and continue through the summer. While flowering of plants in central or south Florida might continue into fall or even winter, the main blooming season is spring and summer. In those regions, discontinue supplemental fertilization by mid-fall.

A controlled-released fertilizer (CRF) can be used for rows that are more than 3 inches wide in landscape fabric systems. If a drip irrigation system has been installed, fertigating will provide more uniform distribution of nutrients to the crop than a CRF.

\section{Irrigation}

Since Leavenworth's coreopsis prefers moist soil, use supplemental irrigation to insure that plants receive at least 1 inch water per week. When applying supplemental water, apply at least 3/4 inch. Applying less might result in a shallow root system that would make plants more susceptible to drought stress. 


\section{Weed Control}

Weeds usually are the major pest problem in wildflower seed crops. They could reduce seed yield by competing with the crop for water and nutrients. And just as important, marketing of the seed will be difficult or impossible if there are too many weed seed mixed in with the crop seed. Be especially thorough when eliminating noxious weed species (2) from your planting. Seed of noxious weed species mixed in with Leavenworth's coreopsis seed will severely limit your ability to sell or distribute your seed, and might even prevent it. For example, the Florida Department of Transportation has zero tolerance for noxious weed species in wildflower seed that they purchase.

Weed control is a major consideration when deciding whether to direct seed or use transplants. Direct seeding is much less expensive than using transplants but there are no herbicides currently labelled for use on seed beds used for wildflower seed production. Hence, some costly handweeding will probably be necessary the first year. The advantage of using transplants is that preemergence herbicides can be used soon after transplanting (see Chemical Weed Control).

Under good growing conditions, Leavenworth's coreopsis will out compete many weeds as it fills in the row. However, even if weed competition seems minimal and the crop is thriving, use practices that will reduce the amount of weed seed that could be harvested with the crop seed.

Cultural Practices. In direct-seeded plots, handweeding will be necessary until seedlings are large enough to permit use of a preemergence herbicide or postemergence grass herbicide. Some handweeding might be necessary in transplant plots even if a preemergence herbicide was used. For example, nutgrass (Cyperus spp.) often is not controlled and must be removed manually or sprayed with a nonselective postemergence herbicide. Eradicate nutgrasses as soon as possible because they can quickly spread.

Mowing can be used to keep weed growth in check as well but mow weeds before they flower and go to seed. Production plots can be mowed until
Leavenworth's coreopsis becomes too tall to remain under the blade. Also, mow the area surrounding the seed production area often enough to prevent weeds from flowering.

Chemical Weed Control. If chemical weed control is to be part of the weed management program, use a preemergence herbicide. Preventing weed growth is usually less expensive than killing existing weeds. Pennant Magnum ${ }^{\mathrm{TM}}$ and Dacthal ${ }^{\circledR}$ $\mathrm{W}-75$ are the only preemergence herbicides currently labeled for use on Coreopsis species. While these herbicides should be safe to use, herbicide tolerance can vary depending on seed source and growing conditions. Testing these herbicides on a small portion of the planting prior to widespread application would be wise. Check for injury for 1 to 2 months after application.

Grasses growing in or around crop plants can usually be controlled with postemergence application(s) of a grass herbicide. The only postemergence grass herbicide specifically labeled for use on Coreopsis species is Acclaim ${ }^{\circledR}$ Extra. Like the preemergence herbicides mentioned above, this herbicide should be tested on a small portion of the crop prior to widespread application.

Existing annual and perennial broadleaf weeds or nutgrasses can be controlled by directed applications of a nonselective herbicide that contains glyphosate or glufosinate as the only active ingredient. Small or immature weeds can be killed with a directed application of a contact herbicide that contains diquat or an herbicidal soap as the only active ingredient. Whenever applying nonselective or contact herbicides, use a shielded spray nozzle to reduce the likelihood of spray drift damaging the crop.

Whenever using any herbicide, read and follow all label directions, including those for protective safety equipment and re-entry intervals.

\section{Other Pests}

No significant insect or disease pests have been observed on Leavenworth's coreopsis seed crops. 


\section{Stand Longevity}

Leavenworth's coreopsis is a good seed producer. Since all seed cannot possibly be harvested, replanting should not be necessary for at least a few years. Field and landscape fabric production plots in Florida are all relatively new, so there is little information about how long a planting will last.

However, it is important to maintain as much of the original genetic diversity as possible. There is some evidence that loss of genetic diversity is minimal for at least the first few generations of seed (3). In crops that reproduce primarily by seed, like Leavenworth's coreopsis, each year's crop would represent a new generation. Generation $0(\mathrm{G} 0)$ is seed from the original native population, with $\mathrm{G} 1$ seed being that harvested from the first year's crop.

There are some practical suggestions that would facilitate preservation of genetic diversity. For landscape fabric plantings, save some of the seed originally used to establish the planting to produce seedlings. Every 3 to 4 years, transplant some of those seedlings in early fall throughout the production plot. For field plantings, it would not be practical to plant enough seedlings to make an impact. In that case, save enough seed from the first harvest to sow in the field in late summer or early fall. Between $1 / 8$ and $1 / 4$ pound PLS per acre should suffice.

\section{Harvesting Seed}

Seed is ripe when the seed head turns dark brown and has a "dried" appearance (Figure 4). Seed (Figure 5) can be harvested at this stage because the seed head opens soon after it turns brown. When the seed head opens, seed will fall to the ground with the slightest disturbance.

There are two approaches to harvesting seed: harvest the unopened seed heads, or harvest just the ripe seed.

\section{Harvesting Unopened Seed Heads}

A combine is most cost efficient when harvesting field crops of 10 acres or more. A combine will harvest the whole crop, whether the seed is mature or not. Plants should reflower, allowing at least a second harvest.

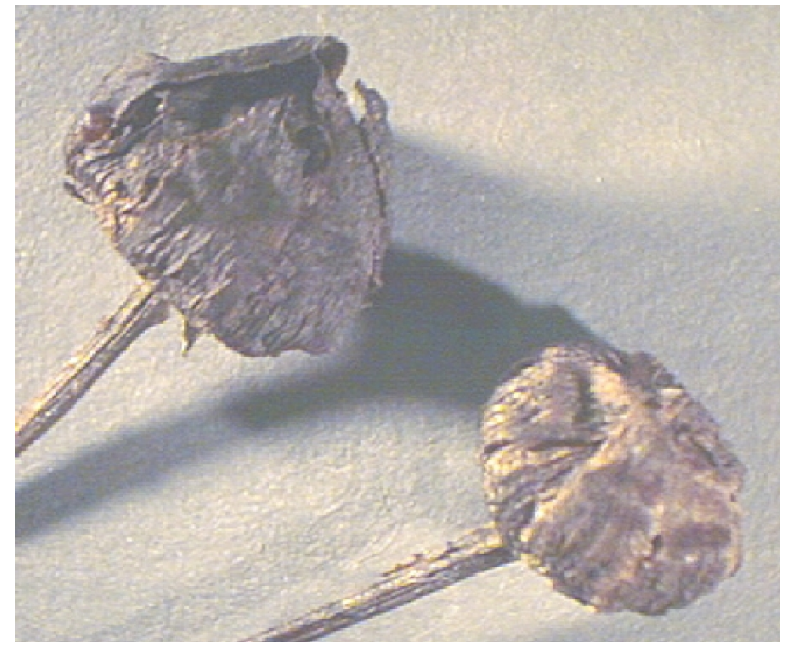

Figure 4. Close up of mature Leavenworth's coreopsis seed head.

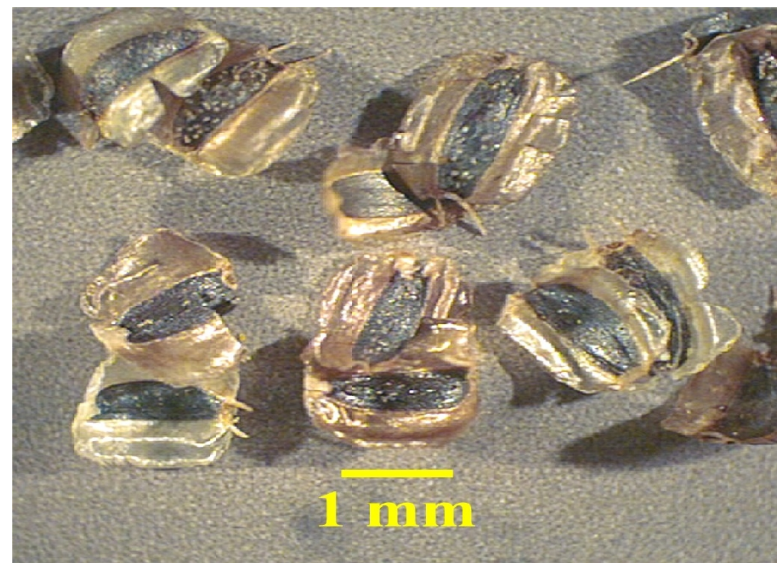

Figure 5. Close up of Leavenworth's coreopsis seed.

Using a handheld seed stripper allows for more selective harvesting. Manually harvesting with pruning shears is the most selective method because seed heads comprised of mostly ripe seed can be harvested.

When seed heads are being harvested from a small plot for increasing seed or for seed packets, harvesting by hand is strongly recommended. Hand harvesting, while labor intensive, will maximize yield (7). Moreover, since only ripe seed heads are being harvested, plants will continuously flower throughout the growing season thereby maximizing seed production.

\section{Harvesting Ripe Seed Only}

The landscape fabric system allows for harvesting of a crop that contains only mature seed. Many ripe seed will fall off the seed head and onto 
the fabric. Vacuum the seed off the fabric several times per week as they could wash away in a storm or be blown away. Black landscape fabric can also get quite hot (over $160^{\circ} \mathrm{F}$ on a sunny day), so exposure of the seed to this heat needs to be minimized. For small production areas, sweeping up seed with a broom might be efficient as well.

\section{Postharvest Drying}

Harvested seed, especially seed harvested by combine, will contain some leaves, stems, and immature seed. Seed must be dried before they are cleaned, and just as important, dried relatively quickly. If the plant material remains moist too long, seed will start to decay.

Harvested seed can be spread on a clean, hard surface and allowed to dry for a few days before cleaning. Use a floor fan to facilitate drying if the harvest is large. Laying the harvested seed on brown packing paper or newspaper in a shed or barn should be adequate. (Visit your local newspaper and ask for the ends of newsprint rolls.) If drying seeds outdoors, seed can be blown away in windy weather, and dew and rain will slow the drying process.

An alternative method is to dry the seed in a drying bin (Figure 6). A simple seed drying bin consists of four plywood walls and a porous false bottom, with warm, dry air $\left(<100^{\circ} \mathrm{F}\right)$ forced up through the bottom. Some growers use a furnace fan as a source of warm air. Openings in the false bottom need to be small enough that seed do not fall through. Spread seed out evenly (and not too thick) over the entire floor of the bin. If part of the false bottom is not covered with seed, the air will preferentially flow through that gap and increase drying time.

\section{Cleaning Seed}

A two-screen (or more) air-screen cleaner can be used to clean Leavenworth's coreopsis seed. If further cleaning is necessary, try replacing screens in the air-screen cleaner with screens of different pore sizes or shapes. Additional cleaning of the seed can also be done with an air density seed separator.

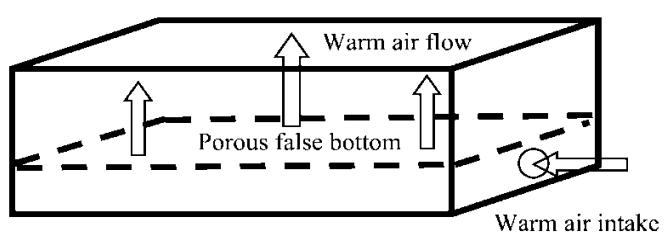

Figure 6. Diagram of a simple seed drying bin.

Small quantities of seed can be cleaned by hand with screens used in an air-screen cleaner. Screens can by purchased for about $\$ 35$ each.

\section{Seed Storage}

Store clean seed in a cool, dry environment such as a large refrigerator or walk-in cooler for maximum shelf life. The current rule of thumb is that temperature $\left({ }^{\circ} \mathrm{F}\right)+$ relative humidity $(\% \mathrm{RH})$ in the storage facility should total 100 or less; RH should be $<50 \%$. For example, storing seed at $35^{\circ} \mathrm{F}$ and $40 \%$ RH $(35+40=75)$ would be adequate.

If seed is going to be stored in a shed or barn, protect seed against insects and rodents. No matter where the seed is stored, each bag should be labeled with the species name, date of harvest, date of storage, percent purity, and percent germination.

\section{Seed Testing and Certification}

Purity and germination tests must be conducted prior to sale. A viability test, which is best when conducted independent of the germination test, is strongly recommended. Total cost for these tests is about $\$ 100$ or more for each wildflower seed crop that will be sold. A viability test is sometimes accepted in lieu of a germination test because a germination protocol for Leavenworth's coreopsis has not been adopted by the Association of Official Seed Analysts (AOSA) or the International Seed Testing Association (ISTA). Protocols published by the AOSA and ISTA are the ones used in seed testing labs. However, Florida state seed law currently requires that germination test results appear on the 
label. Since there is no AOSA or ISTA protocol for Leavenworth's coreopsis, certified labs use their best judgment in selecting an appropriate protocol.

Labs that specialize in testing native species:

Mid-West Seed Services, Inc.

236 32nd Avenue

Brookings, South Dakota 57006

(877) 692-7611

info@mwseed.com

http://www.mwseed.com

Ransom Seed Laboratory, Inc.

PO Box 300

Carpinteria, CA 93014-0300

(805) 684-3427

Ransomsl@silcom.com

http://www.ransomseedlab.com

Some buyers may require that the seed be certified as being Source Identified by the Southern Seed Certification Agency, a joint agency of Florida and Alabama. Certification currently costs $\$ 250$ per year, regardless of the number of species to be certified, plus $\$ 0.10$ per pound of seed to be sold.

Southern Seed Certification Association, Inc.

PO Box 2619

Auburn, AL 36831

(334) 844-4995

http://www.ag.auburn.edu/aux/ssca

\section{Costs}

Detailed information about costs is in the Florida Department of Agriculture Publication "Native Wildflower Seed Production in Florida" (6).

\section{References}

1. Biota of North America Program. 2006. North Carolina Botanical Garden, Chapel Hill. NC. http://www.bonap.org/, (accessed 2 August 2006).

2. Burks, K.C. 2000. Non-native plant species restricted by federal, state, or local law in Florida. Bureau of Invasive Plant Management, Florida Department of Environmental Protection, Tallahassee, FL.

http://www.dep.state.fl.us/lands/invaspec/2ndlevpgs/ pdfs/list.pdf
3.Czarnecki II, DM. 2006. Molecular and morphological diversity of Coreopsis leavenworthii, a Florida wildflower. MS Thesis. University of Florida, Gainesville, FL. 61 p.

4. Jones, T.A. 2005. Genetic principles and the use of native seeds -- just the FAQs, please, just the FAQs. Native Plants J. 6:14-24.

http://www.nativeplantnetwork.org/Content/Articles/ 6-1NPJ14-24.pdf

5. Jones, T.A. and S.A. Young. 2005. Native seeds in commerce: More frequently asked questions. Native Plants J. 6:286-293.

http://muse.jhu.edu/journals/native_plants_journal/ v006/6.3jones.pdf

6. Norcini, J.G. 2006. Native wildflower seed production in Florida. Fla. Coop. Ext. Serv. Publ. ENH 1035. http://edis.ifas.ufl.edu/pdffiles/EP/EP30300.pdf

7. Norcini, J.G., J.H. Aldrich, and F.G. Martin. 2002. Effect of harvest method on seed yield of Coreopsis lanceolata L. and Gaillardia pulchella Foug. J. Environ. Hort. 20:20-23.

8. Norcini, J.G., J.H. Aldrich, and F.G. Martin. 2006. Harvest season and fertilizer effects on seed production of Leavenworth's coreopsis. J. Environ. Hort. 24:63-67. 